\title{
Arsenic pollution in shallow drinking wells in Yuncheng Basin, China: occurrence and mechanisms
}

\author{
C.C. Li \\ School of Environmental Studies, China University of Geosciences, Wuhan, P.R. China
}

\begin{abstract}
High concentrations of arsenic (As) in groundwater has led to adverse effects on human health and ecosystem due to the risk of As toxicity from drinking water sources. Diverse mechanisms govern arsenic mobilization in groundwater. In this study, scatter plot, cluster analysis and factor analysis were employed to investigate the occurrence and mechanisms controlling As concentrations in shallow groundwater at Yuncheng Basin, China. The research shows: (1) As contents in shallow groundwater is closely related to human activity. (2) It is favorable for the release of As in aquifer under reducing environment. Our findings suggest that cautions should be made for the management of shallow As contaminated groundwater.
\end{abstract}

\section{INTRODUCTION}

As a highly toxic element, arsenic (As) widely exists in natural environment (Ayotte et al., 2015; Mahanta et al., 2015; Smedley and Kinniburgh, 2002). Contamination of groundwater, either from natural or anthropogenic processes, has now caused worldwide attention (Currell et al., 2011; Nordstrom, 2002). Millions of people in many countries including China are exposed to elevated levels of As through the uptake of As-rich groundwater. Recently, waterborne As poisoning (arsenicosis) has been found in aquifers in Yanhu District, Yongji City and Linyi County at Yuncheng Basin, northern China.

\section{METHODS AND MATERIALS}

Forty-six shallow groundwater samples were collected across the basin from July to October, 2016. Before sampling, the wells were pumped for over $1 \mathrm{~h}$. At the time of sampling, all groundwater samples were filtered through 0.45 um membranes on site and stored in three new $300 \mathrm{~mL}$ polyethylene bottles which had been rinsed three times with deionized water. For cation analysis, reagent-quality nitric acid $\left(\mathrm{HNO}_{3}\right)$ was added to one of the polyethylene bottles until the $\mathrm{pH}$ of the water sample was less than 2 . Unstable parameters like temperature (T), $\mathrm{pH}$ and electrical conductivity (EC) were measured in situ using portable Hanna EC and $\mathrm{pH}$ meters that had calibrated before use.

Alkalinity was measured on the sampling day using the Gran titration method. Concentrations of anions were determined using IC (Dionex 120). An Intrepid II XSP ICP-AES was used for cation measurements.

\section{RESULTS AND DISCUSSION}

\section{$3.1 \quad$ Scatter plot}

The scatter plot shows As contents in shallow groundwater versus alkalinity, major ions $\left(\mathrm{Na}^{+}, \mathrm{Ca}^{2+}, \mathrm{Mg}^{2+}\right.$, $\mathrm{Cl}^{-}, \mathrm{SO}_{4}^{2-}, \mathrm{HCO}_{3}^{-}$and $\mathrm{NO}_{3}^{-}$) concentrations.

There was a well-defined positive correlation between alkalinity, $\mathrm{SO}_{4}^{2-}, \mathrm{Cl}^{-}$and $\mathrm{NO}_{3}^{-}$with $\mathrm{As}$, indicating the positive contribution of these components to shallow groundwater As (only As vs. $\mathrm{NO}_{3}^{-}$show in Fig. 1). Due to the lack of natural nitrate in most geologic formations, Figure 1 shows that the arsenic

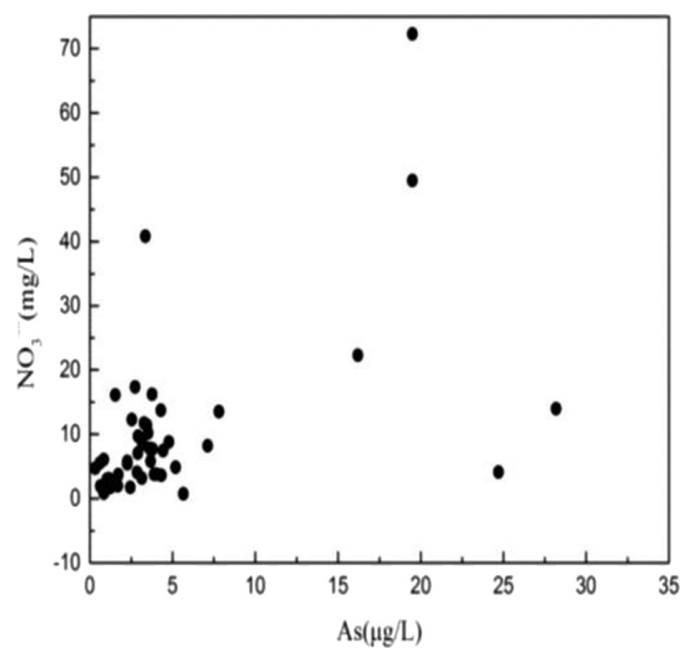

Figure 1. Scatter plot of As and $\mathrm{NO}_{3}^{-}$contents in shallow groundwater. 


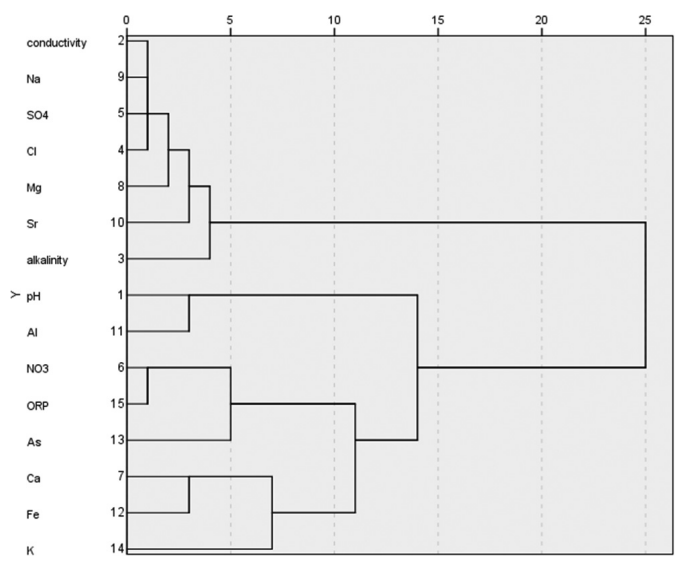

Figure 2. The results of cluster analysis in shallow groundwater.

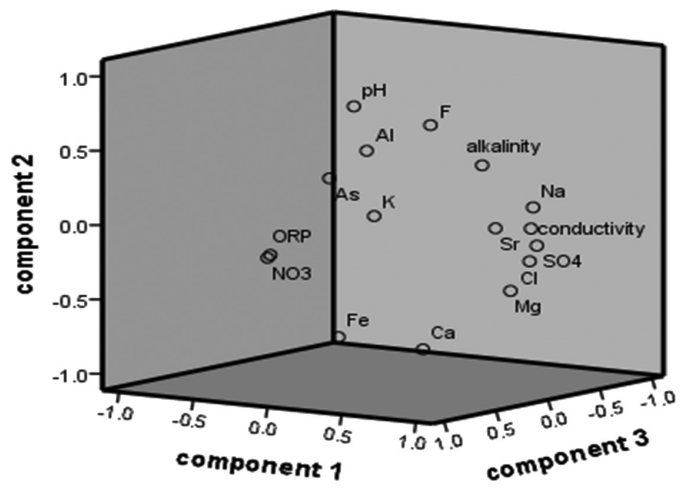

Figure 3. Factor analysis screen plot for shallow groundwater.

in shallow groundwater is closely related to human activities.

\subsection{Cluster analysis}

The cluster analysis (Fig. 2) in the shallow groundwater has shown that the $\mathrm{NO}_{3}^{-}, \mathrm{ORP}$ and As fall into the same cluster. The ORP has a great influence on the enrichment of arsenic in the shallow aquifer and it is favorable for the release of arsenic in aquifer under reducing conditions. Human activity is another important factor affecting the concentration of arsenic in shallow groundwater.

\subsection{Factor analysis}

Factor 1 accounts for most of the total variance $(36.18 \%)$ and is characterized by the associations of conductivity, $\mathrm{Cl}^{-}, \mathrm{SO}_{4}^{2-}$ and $\mathrm{Na}^{+}$, representing anthropogenic pollution such as farmland irrigation and fertilization (Fig. 3).

\section{CONCLUSIONS}

The results of this research showed that:

(1) The concentrations of As in shallow groundwater are affected by the $\mathrm{NO}_{3}^{-}$contents, suggesting the influence of human activities on As in the shallow aquifer.

(2) The ORP has a great influence on the enrichment of arsenic in the shallow aquifer and it is favorable for the release of arsenic in aquifer under reducing conditions.

\section{REFERENCES}

Ayotte, J.D., Belaval, M., Olson, S.A., Burow, K.R., Flanagan, S.M., Hinkle, S.R. \& Lindsey, B.D. 2015. Factors affecting temporal variability of arsenic in groundwater used for drinking water supply in the United States. Sci. Total Environ. 505: 1370-1379.

Currell, M., Cartwright, I., Raveggi, M. \& Han, D.M. 2011. Controls on elevated fluoride and arsenic concentrations in groundwater from the Yuncheng Basin, China. Appl. Geochem. 26(4):540-552.

Mahanta, C., Enmark, G., Nordborg, D., Sracek, O., Nath, B., Nickson, R.T., Herbert, R.B., Jack, G., Mukherjee, A., Ramanathan, A., Choudhury, R. \& Bhattacharya, P. 2015. Hydrogeochemical controls on mobilization of arsenic in groundwater of a part of Brahmaputra river floodplain, India. J. Hydrol. - Regional Studies 4: 154-171.

Nordstrom, D.K. 2002. Worldwide occurrences of arsenic in ground water. Science 296(5576): 2143-2145.

Smedley, P. \& Kinniburgh, D. 2002. A review of the source, behaviour and distribution of arsenic in natural waters. Appl. Geochem. 17(5): 517-568. 